\title{
Implementing a Physical Activity Curriculum into the School Day: Helping Early Childhood Teachers Meet the Challenge
}

\author{
Casey Marie Breslin · Jane R. Morton • \\ Mary E. Rudisill
}

(C) Springer Science+Business Media, LLC 2007

\begin{abstract}
In Fall 2006, North Carolina kindergarten teachers were charged with the task of meeting the NASPE guidelines for providing daily physical activity to their kindergarten students. In turn, the teachers researched resources and consulted experts to design and develop a developmentally appropriate physical activity and physical play environment for their students. The purpose of this article is to disseminate useful information one group of kindergarten teachers believed would help other teachers in similar situations. The article discusses the planning process, suggestions for activities and necessary equipment for program implementation, and vignettes regarding the experiences the teachers and students have had during the physical activity and physical play program's inaugural year.
\end{abstract}

Keywords Early childhood physical education .

Curriculum - Motor skill development

In a number of states across the nation, including North Carolina, classroom teachers are being charged with the task of engaging their students in daily physical activity. This charge is in response to the serious obesity epidemic and sedentary lifestyles of modern day American children. In the past 30 years, the prevalence of overweight children, aged 2-5 years, increased from $5.0 \%$ to $13.9 \%$. The rate of

C. M. Breslin ( $\square) \cdot$ M. E. Rudisill

Department of Kinesiology, Auburn University, 2050 Memorial

Coliseum, Auburn, AL 36849, USA

e-mail: breslcm@auburn.edu

J. R. Morton

Pumpkin Center Elementary School, 3970 King Wilkinson

Road, Lincolnton, NC 28092, USA obesity for children, ages 6-11 years, has more than quadrupled in the past 30 years; increasing from $4.0 \%$ in 1974 to $18.8 \%$ in 2004 , while obesity rates in school-aged adolescents increased from $6.1 \%$ to $17.4 \%$ (Ogden et al. 2006).

From a healthcare perspective, the consequences of childhood obesity are staggering. An estimated $61 \%$ of overweight young people have at least one additional risk factor for heart disease, such as high cholesterol or high blood pressure. Moreover, children who are overweight are at greater risk for bone and joint problems, sleep apnea, endocrine abnormalities, and social and psychological problems such as stigmatization and poor self-esteem. In comparison to their normal weight peers, overweight young people are more likely to become overweight or obese adults, and therefore are more at risk for associated health problems, including heart disease, type II diabetes, stroke, several types of cancer, and osteoarthritis. Furthermore, obesity in adolescence better predicts mortality than obesity in adulthood.

Realizing the seriousness of such health trends, states across the nation are now evaluated on efforts to improve children's health status and to get children more physically active. In a 2004 evaluation of state governments and their efforts to combat obesity, nearly half (23 states) of all US states are failing in their efforts to control the obesity epidemic facing the nation. No state received an "A" for passing laws to help prevent and treat obesity, such as limiting the types of foods and beverages sold in schools and expanding health insurance to cover obesity treatment (Acs and Stanton 2005).

Consequently, many school districts across the US are standing up to the challenge and asking classroom teachers to help combat obesity. This is great news for advocates committed to the health and welfare of our society. However, the realities of implementation are not as spectacular as the 
concept. When asked to implement a new curriculum or curricular approach, most teachers want to know: What resources do I need to implement the curriculum? How do I work it into my planning and daily schedule? How will it impact my students and me? What are the expected outcomes? These questions must be answered because it is at the teacher level where policy meets practice. If the teacher does not understand or value the curricular outcomes, or does not have the resources, training, or confidence to implement it, then nothing will change.

What does this emphasis on physical activity mean for early childhood teachers? The physical activity guidelines recommend that children in early childhood accumulate at least 30 min of planned physical activity on a daily basis (National Association for Sport and Physical Education (NASPE 2004)). The guidelines also encourage early childhood educators to be aware of the importance of physical engagement, and to provide early learning experiences that emphasize health promoting physical activity and motor skill development (NASPE 2004). Additionally, when children meet the physical activity objectives, research indicates that the teacher is probably going to benefit from the physical activity as well (Parish et al. 2007).

Implementing the physical activity curriculum means that the teacher is responsible for "setting the stage" by helping children develop the foundation they need to grow up and be healthy minded, responsible adults (Parish and Rudisill 2006). We suspect that most early childhood teachers have been teaching "healthy lifestyle" content in classrooms for years, but the new physical activity curricular objectives are not the same. The following is an example of how a group of teachers found an exciting approach to promote physical activity and motor skill development that accomplish the objectives of the new curricular objectives encompassing NASPE guidelines that is working for them.

\section{Moving in the Right Direction: Where Policy Meets Practice}

Pumpkin Center Elementary School in Lincolnton, North Carolina has worked to ensure their kindergarteners are learning to be life-long movers and moving to be life-long learners. They have implemented a university-endorsed physical play program during their daily recess and have encouraged the children to move throughout the day while in the classroom. In just one year, the kindergarten teachers at Pumpkin Center have advanced from a free play recess period to a model, planned-high autonomy physical play program promoting both vigorous physical activity and motor skill development.
At Pumpkin Center Elementary, kindergarten teachers were provided with new curricular competencies and objectives to be implemented during the school year that included physical education concepts and a required $30 \mathrm{~min}$ of daily physical activity. The teachers reviewed the new curriculum and utilized the state web-based resource, but still felt somewhat unprepared in meeting the curricular needs. In order to engage the children in physical activity and develop a lifetime appreciation for it, as mandated by the curricular competencies and objectives, the teachers required a better understanding of the foundations of physical education (such as motor skills, body management, and self-management behaviors) and how to facilitate the children to learn the objectives. Specifically, the teachers needed more guidance in implementing an age-appropriate physical activity program and therefore sought additional resources from internal and external sources.

The resulting transitional program has received accolades from the school district, as the kindergarteners are participating and enjoying their daily physical activity program more than ever. To get started, the kindergarten teachers contacted their physical education teacher and principal. Additionally, they searched for developmentally appropriate ideas for implementing physical activity using the internet and print resources. The teachers contacted a university's Department of Kinesiology that provided various resources and materials to develop a quality, age-appropriate physical activity program. ${ }^{1}$ Using these resources, the teachers began their program implementation in the beginning of the 20062007 academic year. The teachers felt sharing their experiences would be beneficial for other teachers facing similar challenges.

\section{Understanding the Competencies}

The Pumpkin Center teachers were comfortable teaching many of the Healthful Living competency goals such as those dealing with emotional well-being, personal health, nutrition, safety, and substance abuse, but were less confident about teaching the competency goals and objectives regarding movement and motor skills (e.g., NC Competencies 6-10) (Standard Course of Study, n.d.). They learned that the movement and motor skills competencies were derived from NASPE's Standards for Physical Education (NASPE 2004), a document used to help operationally define a quality physical education program. Refer to Table 1 for a list of NASPE Standards for Physical Education.

\footnotetext{
${ }^{1}$ Teachers are encouraged to contact universities for help and assistance in such efforts. Many university faculty and students today are involved in service learning and outreach projects and are looking for opportunities to partner with schools in the community.
} 
Table 1 NASPE standards for physical education

NASPE Standard 1 (NC Competency Goal 6)

The learner will demonstrate competency in a variety of movement forms and proficiency in a few to gain competence towards lifetime physical activities.

Objective 1: Demonstrate non-locomotor movements using different parts of the body.

Objective 2: Demonstrate a variety of beginner locomotor and combination skills in a movement pattern.

Objective 3: Develop movement control for safe participation in games and sports.

Objective 4: Demonstrate rolling movements.

NASPE Standard 2 (NC Competency Goal 7)

Demonstrates understanding of movement concepts, principles, strategies, and tactics as they apply to the learning and performance of physical activities.

Objective 1: Identify fundamental movement patterns.

Objective 2: Establish a beginning movement vocabulary.

Objective 3: Apply age appropriate concepts to performance.

NASPE Standard 3 (NC Competency Goal 8)

The learner will exhibit a physically active lifestyle.

Objective 1: Identify likes and dislikes connected with participation in physical activity.

Objective 2: Begin to identify opportunities for increased physical activity (e.g., taking the stairs).

NASPE Standard 4 (NC Competency Goal 9)

The learner will show evidence of an acceptable level of health-related fitness and be familiar with factors that benefit performance.

Objective 1: Identify physiological signs of moderate physical activity.

Objective 2: Recognize two appropriate sites on the body to monitor the heart rate.

Objective 3: Sustain moderate to vigorous physical activity for short periods of time.

Objective 4: Demonstrate knowledge of flexibility through warm up activities and perform exercises that enhance proper flexibility in a variety of muscle groups.

NASPE Standard 5 \& 6 (NC Competency Goal 10)

Exhibits responsible personal and social behavior that respects self and others at the same time as values physical activity for health, enjoyment, challenge, self: expression, and/or social interaction.

Objective 1: Identify 1 to 2 reasons why participation in physical activity is important and enjoyable.

Objective 2: Identify 1 to 2 ways physical activity improves health.

Objective 3: Demonstrate respect for self, others, and equipment.

\section{NASPE Standard 1: Fundamental Motor Skill Development}

The first step for the Pumpkin Center teachers designing lesson plans to meet the physical activity competencies was to determine what behaviors constitute non-locomotor movements, locomotor skills, combination skills, and rolling movements, and how proficient kindergarten children should be at performing these skills. Non-locomotor movements include object control skills such as throwing, kicking, striking, rolling, dribbling, and catching as well as bending, twisting, and swaying skills. Locomotor skills involve moving the body in space and include walking, running, hopping, jumping, galloping, sliding, and skipping. Combination skills connect multiple locomotor skills such as galloping and sliding (i.e., leap in combination with a step) or skipping (i.e., hop in combination with a step). Locomotor and non-locomotor skills serve as the building blocks for engaging in lifetime physical activities such as dance and sport. Rolling movements are defined as ways to maneuver the body through tumbling and body management skills. All these basic skills are not naturally learned but require instruction and practice to learn (Gabbard 2000; Haywood and Getchell 2001; Newell 1984; Newell 1986; Goodway et al. 2002) (Illustration 1).

Once these terms were defined and better understood, the teachers were able to identify a range of proficiency in skill performance for their kindergarteners. See Illustration 2 for a description of the developmental progressions of the motor skills (or refer to a motor development textbook for an illustration of these skills). The teachers were also able to understand how to promote the importance of maintaining personal space and the proper ways to use movement-related equipment to ensure the safety of the children. 
Illustration 1 Putting, striking with a paddle, bouncing, and kicking are examples of Object Control skills
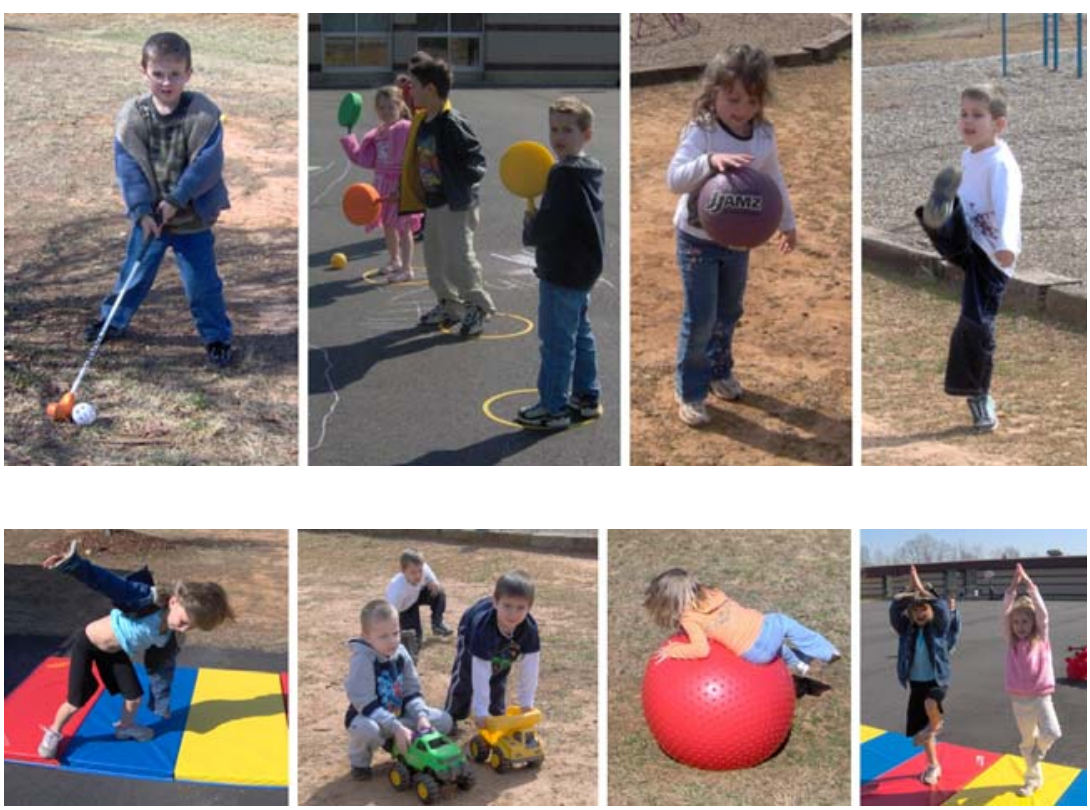

Illustration 2 The activities displayed above promote body management as well as strength and balance

\section{NASPE Standard 2: Movement Concepts, Principles, Strategies, and Tactics}

The most critical component that required clarification for this competency goal was the identification of key phrases to help the children describe and learn the fundamental movement patterns or skills. These phrases enabled the teachers to provide the children with verbal descriptions of the motor skills, especially for those who demonstrated difficulty performing them following observation and demonstration. For example, teachers were told when instructing the overarm throw, reminding children to "stand with your side toward the target, bring the ball back, step with the opposite foot, and reach forward and down with the throwing arm" will elicit a more mature overarm throw. When teachers noticed a child struggling to hop, the child usually performed better if reminded to "lean your body forward" and "place the foot off the ground behind the body (not in front)". The teachers at Pumpkin Center asked the school's physical education teacher, who provides kindergarten physical education once a week, what key words she implemented into her classes. By incorporating the same terminology and key words used by the physical education teacher, some confusion was avoided (Table 2).

The teachers from Pumpkin Center Elementary School found that providing opportunities for the children to talk about movement experiences helped promote a movement vocabulary and ways to describe their own movement experiences. The teachers discovered that when the children talked about and described their movement experiences, the children made important learning connections with information they already knew and the curricular content became more meaningful and authentic. For instance, the teachers at Pumpkin Center started the physical activity program with a motor skill that all the children could perform, running. Based on the interests of the children in each classroom, they discussed or wrote about one or more of the following: What animals are fast runners or slow runners? What is the purpose of running? What is the difference between running and walking? How can you get faster at running? What happens to your body when you run? What happens when you run up or down a hill? How do people run if they are missing a leg or legs?

Beyond these activities that promote the children's movement vocabulary, the teachers created opportunities for the children to learn age appropriate movement concepts. Movement qualities are implemented when a child is presented with a movement challenge, such as leaping over a puddle, and is required to problem solve the task demands. For example, a child has to determine how much force, distance, and speed to use to successfully leap over a puddle. That child has to execute the skill and manage the timing of the skill to avoid landing in the water. Force, time, and space are the foundational qualities of movement. Teachers at Pumpkin Center found ways to emphasize these qualities by offering a variety of developmentally appropriate movement experiences. For instance, they encouraged children to move in contrasting ways (e.g., soft/hard, big/small, fast/slow, straight/curved/zigzag, high/ low, on the floor/in the air). They found that simple movement games (e.g. follow the leader, red light-green light, or dance games) allow practice with qualities that involve "arriving on", "mirroring-matching", "meetingparting", "together-apart", and "following-copying". 
Movement qualities modify motor skills in the following ways: (a) direction (e.g., forward/backward, sideways, across, around), (b) levels (e.g., high/medium/low, over/ under), (c) dimensions (e.g., large/small motions), and (d) expressiveness (e.g., smooth, quick, heavy, jerky, stiff, fluent, bound, free) (Buchanan et al. 2004).

Given that children have different strengths and abilities, a variety of developmentally appropriate activities, ranging in difficulty, should be offered each day on the playground so all children have opportunities to enjoy success at physical activity. Some children prefer boisterous activities including loud, imaginative games, while other children may prefer more calm activities like rolling a ball back and forth with a friend. Early childhood motor activities should steer away from competition and, if designed properly, emphasis on winning or comparison to others should be eliminated or reduced. The teachers at Pumpkin Center Elementary encourage self-improvement on the playground rather than social comparison; reinforce effort not winning; respond to individual accomplishments and privately praise children who are playing hard and cooperating with others (Rudisill and Wall 2004). The teachers avoid stifling the students' creativity and freedom to move by allowing the children to create their own games using the equipment provided, as long as the new game is safe.

Additionally, the teachers found that games older children enjoy are not appropriate for children in early childhood (e.g., kickball or basketball). These children are not ready for the complexities of a structured sporting event. Instead, they should be refining their motor skills through fun, authentic play and modified game experiences. The teachers also found it wise to regularly change the motor activities and let the children participate in deciding what types of activities should be included in the physical activity program each day (Illustration 3).

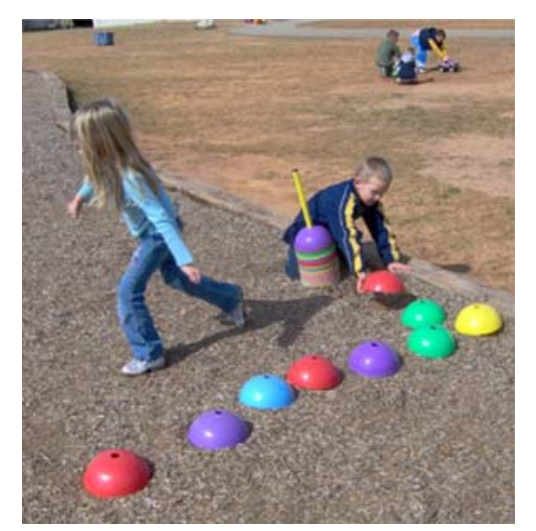

Illustration 3 Kindergarteners create their own game by using the balancing domes or turtles

\section{NASPE Standard 3: Physical Activity Lifestyle}

Providing children with a variety of physical activity opportunities helps children learn their movement preferences. Physical activity does not have to be structured or occur in a formal activity or game. Some children may not like organized movement activities, but they may enjoy dance, yoga, or biking. Discussing the many sources of daily physical activity (e.g. walking the dog, riding a bike, taking the stairs instead of an elevator, or by taking a "brain break" to dance in their personal space) fosters a lifelong appreciation for activity.

Besides locomotor and non-locomotor skills, children should be taught developmentally appropriate games and encouraged to move creatively through dance or rhythm activities. Supplying the children with props may result in vigorous physical activity through imaginative play. For example, Pumpkin Center teachers purchased large pieces of cloth that the children view as superhero capes. When transformed into a superhero while wearing a cape, the children were compelled to run and jump in the air and perform heroic acts (Illustration 4). When provided with ribbons, the children imagined themselves as horses and galloped while using the ribbon as a whip.

When children are introduced to activities from other cultures (e.g. yoga, Chinese jump rope), and modifications to games they already know, they experience an increase in their physical activity repertoire. With increased exposure to a variety of ways to move and be physically active, children are better equipped to make informed decisions regarding their preferences for physical activity.

\section{NASPE Standard 4: Health-Related Fitness}

The Pumpkin Center children learned how to identify physiological signs of moderate physical activity when

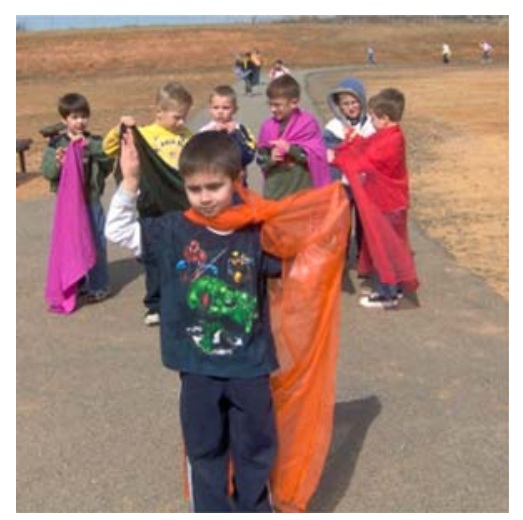

Illustration 4 Teachers find that their kindergarteners are more motivated to run when wearing "superhero clothing" 
prompted with a question such as "What happens when you play really hard and run really fast?". They responded by saying they are "out of breath", "tired", "sweaty", or "thirsty". With prompting, the children recognized that their heart rate increased and were able to identify the sites on the body where they could feel their heart beat (chest, carotid artery on the neck, or the radial artery on the thumb side of the wrist). When their heart rate increased with physical activity, the children were told their hearts were telling them "thank you" for the exercise.

The recommended $30 \mathrm{~min}$ (or more) of physical activity each day does not have to occur all at once. The $30 \mathrm{~min}$ may be accrued throughout the day in little bouts of a few minutes of physical activity at a time. For example, one classroom at Pumpkin Center Elementary starts each day with the "Yoga Pose of the Day". The teacher selects the yoga pose of the day from a poster displayed in the classroom, describes and demonstrates the pose, and then the class joins in holding the pose for a short time. The children really enjoy this activity (as the poses are often named after plants or animals), and have insisted that their substitute teacher practice the "Yoga Pose of the Day" with them. Later in the day, the children may practice their alphabet by performing the Superhero/Cheerleader alphabet, in which the children must stretch their arms above their head for "tall" lower case letters, place their hands on their hips for "medium" lower case letters, and touch their toes for "low" lower case letters while reciting the alphabet. During center time, the teacher might put on a record and the students take a break to perform the "bottom" dance (sit on their buttocks and move their legs and arms in the air to the music) for the duration of the song. Through these simple activities, the children accumulate 10 min of physical activity throughout the day, in addition to the 20 minute recess period that incorporates a highautonomy physical play environment, resulting in an accumulation of the recommended $30 \mathrm{~min}$ of physical activity before the school day ends.

To begin the high-autonomy physical play environment during recess, the teachers at Pumpkin Center Elementary lead the children in running around the track as a warm-up activity using props (e.g., capes and ribbons as mentioned previously, toys with wheels that can be pushed around the track, music to encourage movement, a set of dice for rolling to determine the number of laps traveled around the track, laminated die cuts representing different animals to mimic, etc.). ${ }^{2}$ If running a lap is not possible, the children could be encouraged to dance, perform aerobics, run in

\footnotetext{
2 They are fortunate enough to have access to a track on their recess grounds, however at schools without a track, running in a large circle around the recess grounds is acceptable. It may be wise to place cones or other raised markers around the perimeter of the recess space (e.g. about six feet from the fence or "off limits area") to mark the path the
}

place, or jump around to a fast paced song played on a portable $\mathrm{CD}$ player. Additionally, the students really enjoy a game of chase with the teacher serving as "it". This game does not have to last very long, in fact two to 4 min provides a sufficient warm up. Any activity that gets the children moving their large muscle groups such that their heart rate increases can serve as an appropriate warm up activity.

After the warm up activity, children are free to select their own activities on the recess grounds. A variety of equipment including very large balls that can be chased, scooters that can be pushed and pulled, and hoppy balls for sitting on and bouncing distributed throughout the playground can promote vigorous physical activity. Additionally, there may be a kicking or a throwing activity with a large target in which children attempt to kick or throw different sized and weighted objects (e.g. 3" balls, 4" balls, 8" balls, foam footballs, rag soccer balls, beach balls, and giant balls). Teachers at Pumpkin Center Elementary also place tumbling mats on the playground for a quiet area for children to stretch and work on their flexibility and practice tumbling moves or the "Yoga Pose of the Day". The children are entrusted to select and move from activity to activity at their own pace. Teachers interfere only when the children need instructional assistance or a moderator. Table 3 presents a lesson plan for the Pumpkin Center kindergarten physical activity program.

The kindergarten teachers at Pumpkin Center had minimal gross motor equipment prior to starting their program. They learned that by setting up multiple activity stations, it is not necessary to have one piece of equipment for every child. Throughout the year, the teachers acquired equipment. With one small donation and some careful planning, they were able to purchase a few different types of balls, a few scooters, lots of "whips" and "capes", a few mats, balloons and scarves, some plastic domes and cones, a few age-appropriate hockey sticks and golf putters, paddles, etc. They asked the physical education teacher and university resource for help in ordering the types of equipment that would best meet the needs of their children while meeting the curricular objectives. All the kindergarten teachers work cooperatively in sharing the equipment with each other. When possible, each teacher makes contributions to the equipment collection, and they ask the community to make contributions by donating tricycles, scooters, balls, bats, and more to their effort.

Footnote 2 continued

students should follow while running since young children have trouble with Euclidean or flat boundaries. 
Table 2 A description of the developmental progressions for fundamental motor skills (Locomotor,object control, and combination skills): the movement arts fundamental gross motor skill development

\begin{tabular}{|c|c|c|c|}
\hline & Level A: Early understandings & Level B: Transitional understandings & Level C:Operational understandings \\
\hline \multirow[t]{2}{*}{ Throw } & $\begin{array}{l}\text { Vertical arm wind-up; Chop throw; Feet } \\
\text { stationary; No spinal rotation }\end{array}$ & $\begin{array}{l}\text { High arm wind-up; Step with same } \\
\text { foot as throwing arm; Little spinal } \\
\text { rotation; Arm follow-through across } \\
\text { body }\end{array}$ & $\begin{array}{l}\text { High wind-up; Step with opposite foot } \\
\text { as throwing arm; Little spinal } \\
\text { rotation; Arm follow-through across } \\
\text { body }\end{array}$ \\
\hline & $\begin{array}{l}\text { Horizontal arm wind-up; "Sling throw," } \\
\text { Block rotation of trunk/body; Arm } \\
\text { follow-through across body }\end{array}$ & & $\begin{array}{l}\text { Arm moves in downward arc wind-up; } \\
\text { Step with opposite foot as throwing } \\
\text { arm; Body segmentally rotates; } \\
\text { Arm and leg follow-through }\end{array}$ \\
\hline \multirow[t]{2}{*}{ Catch } & $\begin{array}{l}\text { Delayed arm action-Arms straight in } \\
\text { front of body until ball contact then } \\
\text { scoops object to chest; Feet stationary }\end{array}$ & $\begin{array}{l}\text { Arms "scoop" under object to trap it } \\
\text { to chest; Single step may be used to } \\
\text { approach ball }\end{array}$ & $\begin{array}{l}\text { Catch with hands only; Feet stationary } \\
\text { or limited to one step }\end{array}$ \\
\hline & $\begin{array}{l}\text { Arms encircle ball as it approaches- } \\
\text { object is hugged to chest; Feet } \\
\text { stationary or may take one step }\end{array}$ & & $\begin{array}{l}\text { Catch with hands only; Whole body } \\
\text { moves through space to get in } \\
\text { position to catch the object }\end{array}$ \\
\hline \multirow[t]{2}{*}{ Kick } & $\begin{array}{l}\text { Little to no leg wind-up; Stationary } \\
\text { position; Foot "pushes"Object ; may } \\
\text { step backward after kicking }\end{array}$ & $\begin{array}{l}\text { Slow moving approach toward the } \\
\text { object; Foot travels in a low arc; } \\
\text { Arm on opposite side of body }\end{array}$ & $\begin{array}{l}\text { Rapid moving approach toward } \\
\text { object; Backward trunk lean during } \\
\text { wind-up; Leap before kick; Hop }\end{array}$ \\
\hline & $\begin{array}{l}\text { Leg wind-up; to the rear; Stationary } \\
\text { position; Opposite of arms and legs }\end{array}$ & $\begin{array}{l}\text { moves; Forward or sideward step on } \\
\text { follow-through }\end{array}$ & after object contact \\
\hline \multirow[t]{2}{*}{ Strike } & $\begin{array}{l}\text { Arms and striking implement move } \\
\text { downward-"Chop strike action; Feet } \\
\text { stationary }\end{array}$ & $\begin{array}{l}\text { Arms strike across the body- } \\
\text { Horizontal push swing; Block } \\
\text { rotation of trunk/body; Feet } \\
\text { stationary }\end{array}$ & $\begin{array}{l}\text { Step with opposite foot as inside } \\
\text { striking arm; Body segmentally } \\
\text { rotates; Wrist rolls over and follows } \\
\text { through }\end{array}$ \\
\hline & & $\begin{array}{l}\text { Step with same foot as inside arm; } \\
\text { Arms and striking implement move } \\
\text { diagonal \& downward }\end{array}$ & \\
\hline \multirow[t]{2}{*}{$\begin{array}{l}\text { Long Jump } \\
\text { ( } 2 \text { foot take-off } \\
\text { and landing) }\end{array}$} & $\begin{array}{l}\text { Arms acts as "brakes"-move backwards; } \\
\text { Body travels vertically when jumping; } \\
\text { Legs do not extend }\end{array}$ & $\begin{array}{l}\text { Arms move forward-elbows move in } \\
\text { front of trunk attake-off-Hands } \\
\text { move to head height during jump; }\end{array}$ & $\begin{array}{l}\text { Complete arm and leg extension at } \\
\text { take-off; Take-off near } 45 \text { degree } \\
\text { anle; Thighs parallel to surface }\end{array}$ \\
\hline & $\begin{array}{l}\text { Arms acts as "wings"-move in a circular } \\
\text { motion from front to back; Body travels } \\
\text { vertically when jumping; Legs near full } \\
\text { extension }\end{array}$ & $\begin{array}{l}\text { Take-off angle is greater than } 45 \\
\text { degrees; Legs often fully extend }\end{array}$ & when feet contact for landing \\
\hline \multirow[t]{2}{*}{$\begin{array}{l}\text { Hop (1 foot } \\
\text { take off } \\
\text { and landing) }\end{array}$} & $\begin{array}{l}\text { Non-support knee \& foot is held in front of } \\
\text { support leg; Body erect; Hands are } \\
\text { shoulder height }\end{array}$ & \multirow{2}{*}{$\begin{array}{l}\text { Non-support thigh vertical with } \\
\text { support leg- foot behind support leg } \\
\text { with knee flexed; More forward } \\
\text { body lean; Both arms moving } \\
\text { together }\end{array}$} & \multirow{2}{*}{$\begin{array}{l}\text { Non-support leg moves in pendular } \\
\text { action; More forward body lean; } \\
\text { Arms move in opposition with } \\
\text { swing leg }\end{array}$} \\
\hline & $\begin{array}{l}\text { Non-support knee flexed with knee in front } \\
\text { and foot behind support leg; Slight body } \\
\text { lean forward; Both arms moving } \\
\text { toghther }\end{array}$ & & \\
\hline $\begin{array}{l}\text { Gallop ( } 1 \text { foot } \\
\text { remains behind } \\
\text { lead foot) }\end{array}$ & $\begin{array}{l}\text { Resembles a rhythmically uneven run; } \\
\text { trail leg cross in front of the lead leg } \\
\text { during flight and contacts surface in } \\
\text { front of lead leg }\end{array}$ & $\begin{array}{l}\text { Slow-moderate tempo during gallop- } \\
\text { choppy rhythm; Trail leg stiff and } \\
\text { drags behind lead leg; Hips may be } \\
\text { oriented sideways; Body travels } \\
\text { vertically }\end{array}$ & $\begin{array}{l}\text { Smooth, rhythmical pattern- } \\
\text { moderate tempo; Feet remain close } \\
\text { to ground: hips oriented forward }\end{array}$ \\
\hline $\begin{array}{l}\text { Skip (step-hop } \\
\text { combination } \\
\text { rhythmical skill) }\end{array}$ & $\begin{array}{l}\text { Brown skip pattern or irregular rhythm; } \\
\text { Slow, deliberate movement; Ineffective } \\
\text { arm action }\end{array}$ & $\begin{array}{l}\text { Rhythmical skip pattern; Arm provide } \\
\text { body lift and excessive vertical } \\
\text { action of body }\end{array}$ & $\begin{array}{l}\text { Arm action-hands bellows } \\
\text { shoulders; Easy, rhythmical } \\
\text { movement; Support foot near } \\
\text { surface on hop }\end{array}$ \\
\hline
\end{tabular}

Adapted with permission from the Michigan State University Motor Performance Study-Taken from Rudisill et al. (2006) 
Table 3 Pumpkin center kindergarten physical activity—lesson plan

Skill of the week: run

Instant activity: Run around the track 1 lap. (Must have a flight stage where both feet are off the ground to run. Advanced running involves moving arms at sides and knees bent at 90 degree angle [heels of feet near buttocks when kicking up]).

Related classroom activities: Children write in their journals about why running is fun (Language Arts) and create illustrations of children running (Creative Arts). During Circle Time the children talk about the reasons they think running is fun and take a class vote to see how many children like to run and how many do not like to run (Social Studies). Each class member keeps a running log of the laps they complete and estimate the number of laps around the track the class can achieve in one day (Mathematics). Create a graph on the computer showing how many laps are run each day (Technology). Turtles (Plastic balance domes) and personal space and boundaries-instructional time should be spent emphasizing safety, equipment rules (check with the physical education teacher about safety and equipment rules and use her verbal cues and commands for consistency).

Activities: Spread out plastic domes (called turtles) on grassy area. Ask children to find a turtle and stand beside it. Turtles should be spread out to allow children to move freely. As children progress throughout the week with managing their personal space, move the turtles closer together. Turtle activities can include:

a. Learn and remember the turtle's color and location relative to the other children in the class.

b. Walk (slow, fast, high, low) around the turtle. Walk backwards around the turtle.

c. Balance on the turtle with 2 feet, with 1 foot, with hands by-your side, with hands in the air. Count how long you can balance.

d. Run (slow, fast, high, low) around your turtle.

e. Leap (slow, fast, high, low) around the turtle. Leap over and behind the turtle, and from side to side. Leaping involves a 1 foot take-off and landing on the other foot and there must be a flight stage where both feet are off the ground.

f. Jump (slow, fast, high, low) around the turtle. Jump over and behind the turtle, from side to side. Jumping involves a 2 foot take-off and landing and a flight stage where both feet are off the ground. Instructional Tip: Reach high

g. Hop around the turtle on each foot. Hopping involves a 1 foot take-off and landing and a flight stage where both feet are off the ground. Instructional Tip: Keep foot behind knee.

h. Gallop around the turtle.

i. Slide around the turtle.

j. Toss a beanbag while standing on turtle. Toss low and higher.

k. Balance on turtle and move a ribbon to music, balance a beanbag on your shoulder, head, elbow, wrist.

1. Teacher modeling: Teaching should demonstrate running and a love for it.

Playground (learning and applying rules and safety practices—let children be involved in developing playground rules—children should create signage and laminate for physical play period). Social discussions during circle time about how it feels when someone violates the playground rules.

Slow breathing and relaxation activities (e.g., shake off any left-over wiggles, close eyes, breathe slowing and deeply, slow stretching-neck, back, arms, legs, imagery_ of something calm and soothing, relaxing music can be incorporated) to cool down and practice relaxationinstructional opportunity includes talking about mental and physical relaxation and why it is so important.

\section{NASPE Standards 5 and 6: Exhibits Responsible Behavior and Values Physical Activity}

The teachers remind children that the side effects of exercise (e.g. increased heart rates and sweating) are the body's way of showing its appreciation for allowing it to move, and that exercise will help their bodies grow and develop better. In turn, the children recognize the cause and effect relationship between physical activity and the body's responses. The children have learned that as one continues to engage in regular physical activity the negative side effects (i.e. breathlessness and muscle soreness) are not as noticeable.

During circle time, center time, meal time and other instructional opportunities throughout the day, the teachers connect physical activity to the classroom by teaching about the human body and how it works, and how exercise can improve health. Children also learn respect for themselves and for others while testing their physical capacities during physical activity. Safely learning how to run, jump, or move creatively, and the difficulties that come along with learning these movements, help children understand what they can accomplish and what they need to improve. The simple act of requiring the children to clean the playground or classroom used for physical activity and to place equipment in its proper storage area can help the children learn respect for the equipment. The teachers allowed the children to provide input as to what are appropriate behaviors on the playground and have given the children useful labels for identifying where the equipment belongs when put away, thereby helping the children learn how to clean and take care of the equipment.

\section{Summary}

Early childhood teachers are being asked to help fight childhood obesity by providing appropriate physical 
activity opportunities for the children they teach. To avoid negative outcomes and to ensure that their children get the needed physical activity to be healthy, the kindergarten teachers at Pumpkin Center Elementary School in Lincolnton, North Carolina have found the answer through an innovative physical activity program. It is hoped that their knowledge and experiences gained over the past year will serve beneficial to other early childhood teachers equally committed to the well-being and health of the children they teach.

\section{References}

Acs, Z., \& Stanton, K. (2005). The infrastructure of obesity and the obesity epidemic. Journal of Health Economics and Health Policy, 4(3), 139-146.

Author Unknown. (n.d). Standard course of study: Healthful living education-Kindergarten. Retrieved March 22, 2007, from http://www.learnnc.org/scos/2006-HLE/K/.

Buchanan, A., Groccia, C., Rudisill, M. E., \& Taylor, J. (2004). Global bridges curriculum. Beijing, China: Simplex, Inc.

Gabbard, C. P. (2000). Lifelong motor development (3rd ed.). Dubuque, IA: Brown \& Benchmark.

Goodway, J. D., Rudisill, M. E., \& Valentini, N. C. (2002). The influence of instruction on catching: A developmental approach. Motor Development: Research \& Reviews (Vol. 2). Reston, VA: AAHPERD Publications.
Haywood, K. M. \& Getchell, N. (2001). Life span motor development (3rd ed.). Champaign, IL: Human Kinetics.

National Association for Sport and Physical Education. (2004). Moving into the future: National standards for physical education (2nd ed.). Reston, VA: Author.

Newell, K. (1984). Physical constraints on the development of motor skills. In J. Thomas (Ed.), Motor development during preschool and elementary years (pp. 105-120). Minneapolis, MN: Burgess.

Newell, K. (1986). Constraints on the development of coordination. In M. G. Wade \& H. T. Whiting (Eds.), Motor development in children: Aspects of coordination and control (pp. 341-360). Dordrecht, The Netherlands: Nij.

Ogden, C. L., Carroll, M. D., Curtin, L. R., McDowell, M. A., Tabak, C. J., \& Flegal, K. M. (2006). Prevalence of overweight and obesity in the United States, 1999-2004. Journal of the American Medical Association, 295, 1549-1555.

Parish, L. E., \& Rudisill, M. E. (2006). HAPPE: Promoting physical play among toddlers. Young Children, 61(3), 32.

Parish, L. E., St. Onge, P. M., Farquar, C. A., Breslin, C. M., \& Rudisill, M. E. (2007). Mastery motivational motor skills program: Influence on heart rate and physical activity levels in pre-service teachers. Paper presented at the annual meeting of the North American Society for the Psychology of Sport and Physical Activity, June 7-9, San Diego, CA.

Rudisill, M. E., Taylor, J., Buchanan, A., Groccia, C., \& Lectner, J. (2006). Global bridges learning themes. Beijing, China: Simplex, Inc.

Rudisill, M.E., \& Wall, S. J. (2004). Meeting active start guidelines in the ADC-Boykin program: Preschoolers Teaching Elementary Physical Education, 15, 25-29. 